Check for updates

Cite this: RSC Adv., 2019, 9, 38998

\title{
Carbon nanotube reinforced polyvinyl alcohol/ biphasic calcium phosphate scaffold for bone tissue engineering
}

\author{
Weiwei Lan, ${ }^{\text {ab }}$ Xiumei Zhang, ${ }^{a}$ Mengjie Xu, ${ }^{a}$ Liqin Zhao, ${ }^{a}$ Di Huang, (DD *ab \\ Xiaochun $\mathrm{Wei}^{\mathrm{C}}$ and Weiyi Chen ${ }^{\star a b}$
}

In this paper, a well-developed porous carbon nanotube (CNT) reinforced polyvinyl alcohol/biphasic calcium phosphate (PVA/BCP) scaffold was fabricated by a freeze-thawing and freeze-drying method. The microstructure, mechanical properties and the composition of the scaffolds were characterized by field emission scanning electron microscopy (FE-SEM), X-ray diffraction (XRD) and Fourier-transform infrared spectroscopy (FTIR). The results illustrate that after the incorporation of CNTs, the compressive strength of the hydrogels (moisture state) reached $81 \pm 6 \mathrm{kPa}$, presenting a significantly higher value than that of pure PVA/BCP hydrogels $(48 \pm 2 \mathrm{kPa}$ ). Meanwhile, CNT reinforced PVA/BCP scaffolds exhibited a porous structure and high interconnectivity $(80 \pm 0.6 \%)$. The degradation analysis indicated that the degradation ratio of scaffolds can be varied by changing the concentrations of BCP powders and CNTs. Cell culture results show that PVA/BCP/CNT porous scaffolds have no negative effects on the survival and proliferation of cells. These results strongly show that the composite scaffolds may possess a potential application in the field of bone tissue engineering and regeneration.

Received 20th October 2019

Accepted 12th November 2019

DOI: 10.1039/c9ra08569f

rsc.li/rsc-advances
Tissue engineering technology offers an alternative solution to avoid these problems. Bone tissue engineering includes three core factors: scaffolds, seed cells and growth factors. ${ }^{4}$ Among the three factors, the scaffolds should be biocompatible, bioabsorbable, non-toxic and highly interconnected porous. They could provide a suitable environment for cell attachment, proliferation, differentiation and mechanical stability in the defect region, supporting cell growth or serving as a drug or growth factor delivery vehicle. ${ }^{5}$

To mimic the components and the structure of natural bone, a large number of scaffolds are prepared from bioceramics, biocompatible polymers and their compounds. Among these materials, HA and $\beta$-tricalcium phosphate ( $\beta$-TCP) are widely used. ${ }^{6,7} \mathrm{HA}$, as the main inorganic component in bone tissue, presents good bioactivity, biocompatibility as well as bone conductibility. ${ }^{1,7}$ However, pure HA scaffolds are brittle, with low toughness and slow degradation, which cannot meet the requirements of bone repairment. Compared to HA, $\beta$-TCP exhibits a higher solubility, and it could be resorbed in vivo much more quickly. At present, the research of biological materials is focused on mixing different kinds of biological materials together. High-performance composite materials are used to avoid the disadvantages of onefold component materials. Therefore, BCP is one of the ideal options to introduce into bioceramic materials to overcome the disadvantages of single materials. ${ }^{8-10}$

As a supporting material, PVA has gained popularity for tissue engineering applications, ${ }^{\mathbf{1 1 - 1 4}}$ especially as an 
osteochondral scaffold due to its good mechanical properties, non-toxicity, good biocompatibility and biotribological properties. ${ }^{15-17}$ Asran et al. ${ }^{6}$ fabricated a bone scaffold by an electrospinning method. The results show that both the tensile strength and elastic modulus of PVA/n-HAp hydrogels are higher than those of pure PVA hydrogels. Increasing the n-HAp concentration first leads to an increase in hydrogels' tensile strength and then a decrease. The tensile strength of the composite reached the maximum at a concentration of n-HAp up to $5 \%$. With further increase in the n-HAp concentration, up to $10 \%$, the tensile strength began to decrease. Yao et al. ${ }^{17}$ fabricated $\beta$-TCP/PVA bilayered hydrogels for osteochondral repairment. According to their findings, the tensile and compression properties of the hydrogel are markedly improved with the increase in the $\beta$-TCP concentration. Cell culture results confirm that $\beta$-TCP plays a significant role in promoting chondrocyte proliferation. The design of the bilayered osteochondral hydrogel would be helpful in articular cartilage repairment. Up to now, none of these scaffolds have been suitable for bone repair requirements in all respects. The major challenge is to ensure appropriate pore size and a certain stiffness. Although PVA and BCP revealed a high biocompatibility, the relatively weak mechanical properties, which cannot meet the demand of bone substitutes, prevent researchers from further studying them.

Since discovered by Iijima in 1991, CNTs have attracted much attention because of their unique mechanical, thermal and electrical properties. ${ }^{18}$ In recent years, more and more attention has been paid to CNTs or carbon fibers due to their good biocompatibility and electrical performance. ${ }^{19-22}$ Some related studies have indicated that CNTs improve the mechanical properties of HA ceramics without affecting their biocompatibility. ${ }^{\mathbf{2 1 , 2 3}}$ CNTs could be uniformly dispersed into hydrogels or solid composites and set as stress points when the constructs are subjected to a dynamic load. Therefore, it is reasonable to use CNTs to reinforce the mechanical properties of hydrogels.

In this work, CNT reinforced PVA/BCP hydrogels were fabricated, and then, the porous PVA/BCP/CNT bone scaffolds with highly interconnected internal structures were prepared through a freeze-thawing and freeze-drying method. These samples were evaluated for their microstructure, mechanical properties, composition and other aspects. Moreover, cytocompatibility and proliferation of the hydrogels were also studied in vitro.

\section{Materials and methods}

\subsection{Materials}

PVA-117 (MW 145 000) was purchased from Aladdin, China. Sodium phosphate dodecahydrate $\left(\mathrm{Na}_{3} \mathrm{PO}_{4} \cdot 12 \mathrm{H}_{2} \mathrm{O}\right)$ and calcium nitrate tetrahydrate $\left(\mathrm{Ca}\left(\mathrm{NO}_{3}\right)_{2} \cdot 4 \mathrm{H}_{2} \mathrm{O}\right)$ were obtained from Tianli Chemical Co., Ltd. (Tianjin, China). The multiwall carbon nanotubes (MWNTs) were obtained from Nanjing XFNANO Materials Tech Co., Ltd. Other chemicals were purchased from Puxing Chemical Co., Ltd. (Taiyuan, China). All reagents were of analytical grade.

\subsection{Preparation of BCP powder}

BCP powder was produced by an aqueous precipitation reaction method. Briefly, $\mathrm{Ca}\left(\mathrm{NO}_{3}\right)_{2} \cdot 4 \mathrm{H}_{2} \mathrm{O}$ solution was added dropwise into $\mathrm{Na}_{3} \mathrm{PO}_{4} \cdot 12 \mathrm{H}_{2} \mathrm{O}$ solution, adjusting the molar ratio of $\mathrm{Ca} / \mathrm{P}$ to 1.6 at room temperature and $\mathrm{pH}=10$ using acid-base buffers. Then, the synthesized white product was thoroughly washed several times with distilled water to remove the buffer. The obtained powder was heated by a gradient temperature method up to $1150{ }^{\circ} \mathrm{C}$ to produce BCP. The BCP powder was pulverized using a stainless steel mortar and pestle, and then separated using stainless steel sieves to ensure that the diameters of particles are $<40 \mu \mathrm{m}$.

\subsection{PVA/BCP/CNT porous scaffold fabrication}

Porous PVA/BCP/CNT scaffolds were fabricated by a method of freeze-thawing and freeze-drying. To be brief, a $10 \mathrm{wt} \%$ PVA solution was prepared by dissolving dry PVA (10 g) in distilled water $(100 \mathrm{~mL})$ and it was stirred at $90^{\circ} \mathrm{C}$ for $4 \mathrm{~h}$. Then, the BCP powder was dispersed in the PVA solution and stirred for another $4 \mathrm{~h}$ ( $5 \mathrm{wt} \%$, compared to the final weight of the scaffold). Different weight ratios of CNT powder were dispersed into the mixed solution and stirred to make sure that they were dispersed homogeneously $(0.05 \%, 0.25 \%, 0.5 \% \mathrm{wt} \%$, compared to the final weight of the scaffold). The final blended solution was ultrasonicated. Then, the obtained solution was moved into suitable 24-well plates, followed by freezing at $-20{ }^{\circ} \mathrm{C}$ for five freeze-thaw cycles $(20 \mathrm{~h}$ at $-20{ }^{\circ} \mathrm{C}$ and $4 \mathrm{~h}$ at room temperature). The schematic illustration of the synthesis of hydrogels was shown in Fig. 1. The hydrogels were further lyophilized with a freeze dryer (Bilon F-1A-80, China) to form porous scaffolds at $-80{ }^{\circ} \mathrm{C}$ for $48 \mathrm{~h}$.

\subsection{Physicochemical properties of the scaffolds}

2.4.1 Scanning electron microscopy. The micromorphologies of pure BCP powders, PVA, PVA/BCP and PVA/ $\mathrm{BCP} / \mathrm{CNT}$ scaffolds were observed under a scanning electron microscope (SEM, Jeol JSM-7100F, Japan). Before examination, each sample was sputtered with platinum (Pt). The pore diameters of scaffolds were calculated from SEM pictures by the Image J program. The elemental content of BCP powder and scaffolds were examined using an energy-dispersive X-ray spectrometer (EDS, OXFORD X-Max ${ }^{\mathrm{N}}$, UK) with SEM. The distribution of elements was analyzed by an integrated mapping software.

2.4.2 X-ray diffraction. Different samples were analyzed by X-ray diffraction (XRD, Ultima IV, Rigaku Corporation, Japan). The diffractometer was operated at $40 \mathrm{kV}$ and $35 \mathrm{~mA}$. Scanning was performed with the $2 \theta$ values ranging from $10^{\circ}$ to $80^{\circ}$ at a rate of $0.05^{\circ} \mathrm{s}^{-1}$.

2.4.3 Fourier-transform infrared spectroscopy. Fouriertransform infrared spectroscopy (FTIR) spectra of the pure BCP powder and PVA, PVA/BCP, and PVA/BCP/CNT scaffolds were obtained by using an FTIR Spectrometer (Bruker Alpha, Germany) in the transmittance mode within the range of 4000$800 \mathrm{~cm}^{-1}$ to identify the functional groups. Samples were mixed with $\mathrm{KBr}$ pellets to prepare the specimens for FTIR spectroscopy. 
2.4.4 Porosity. The scaffolds porosity $(n=5)$ was measured by the liquid displacement method. To be brief, a hydrogel with a known weight $\left(W_{1}\right)$ and volume $(V)$ was lyophilized with a freeze dryer. Then, the weight of the scaffold was measured as $\left(W_{2}\right)$. $\rho$ represents the distilled water density at the measurement temperature. The porosity $(\varphi)$ of each scaffold was measured as follows:

$$
\varphi=\left(W_{1}-W_{2}\right) /(V \rho) \times 100 \%
$$

2.4.5 Mechanical properties. The mechanical properties of different samples were studied by unconfined compression testing by a universal mechanical testing machine $(50 \mathrm{~N}$, Instron 5544, US). The hydrogels $(n=5)$ were held between two platens. Compression test with a maximum compression strain of $50 \%$ was performed at a speed of $2 \mathrm{~mm} \mathrm{~min}^{-1}$. The elasticity modulus was measured by the slope of a linear fit to the stressstrain curve over $10 \%$ strain.

2.4.6 Moisture content and swelling ratio. Moisture content of hydrogels $(n=5)$ was tested and the swollen hydrogels were weighed $\left(W_{3}\right)$ after removing the surface liquid by a filter paper. Then, the hydrogels were dried at $70{ }^{\circ} \mathrm{C}$ for $24 \mathrm{~h}$ and weighed $\left(W_{4}\right)$. The percent of moisture content was calculated by the following equation:

$$
\varphi=\left(W_{3}-W_{4}\right) / W_{3} \times 100 \%
$$

Swelling ratio of scaffolds $(n=5)$ was calculated after immersing pre-weighed cylindrical dry scaffolds $\left(W_{5}\right)$ in $5 \mathrm{~mL}$ distilled water. After removing the surface liquid by a filter paper, the weights $\left(W_{6}\right)$ of swollen hydrogels were measured. The swelling ratio was obtained according to the following equation:

$$
\varphi=\left(W_{6}-W_{5}\right) / W_{5} \times 100 \%
$$

2.4.7 Degradation in lysozyme solution. To evaluate the degradation of the scaffolds in vitro, pre-weighed scaffolds $\left(W_{7}\right)$ were placed in PBS medium, which contained $0.4 \mathrm{mg} \mathrm{mL} \mathrm{m}^{-1}$ lysozyme at $37^{\circ} \mathrm{C}$ for several weeks. The solution was renewed every 3 days to maintain the lysozyme activity. Each week, a set of aged specimens $(n=5)$ was removed and washed 3 times by distilled water. Then, the scaffolds were dried at $70{ }^{\circ} \mathrm{C}$ for $24 \mathrm{~h}$. The scaffold's $\left(W_{8}\right)$ weight in dry conditions was obtained. The degradation ratio of the scaffolds was obtained by the following equation:

$$
\varphi=\left(W_{7}-W_{8}\right) / W_{7} \times 100 \%
$$

\subsection{Culture of MC3T3-E1 cells}

All scaffolds were sterilized using an autoclave sterilizer. Then, scaffolds were washed three times in $\alpha$-minimum essential medium $(\alpha$-MEM) before seeding. Newborn mouse calvariaderived MC3T3-E1 subclone 14 preosteoblasts were sourced from the Shanghai Cell Bank of the Chinese Academy of Sciences. MC3T3-E1 cells were cultured in $\alpha$-MEM, which contained $10 \%$ fetal bovine serum and $1 \%$ antibiotic/antimycotic compound at $37{ }^{\circ} \mathrm{C}$ in a $5 \% \mathrm{CO}_{2}$ humidified environment. MC3T3-E1 cells were digested with $0.05 \%$ trypsin/EDTA, and then suspended in fresh media. In order to observe the cell attachment condition on each scaffold, the pre-treated scaffolds were placed in the bottom of a 24 -well cell-culture plate and the cell suspension liquid was seeded on them. The morphologies of cells on the scaffolds were observed by SEM after culture at day 1 . Briefly, the scaffolds with cells were transferred from the 24-well plate and washed thrice using phosphate-buffered saline (PBS); then, the specimens were fixed with $2.5 \%$ glutaraldehyde for $40 \mathrm{~min}$. After washing in PBS three times, samples were dehydrated in varying concentrations of ethanol solutions (30\%, 50\%, 70\%, 90\%, 95\% and 100\%, respectively). After coating a thin layer of gold, cell-seeded scaffolds were observed using SEM.

Autoclave sterilized freeze-dried scaffolds were placed inside a sterile centrifuge tube and immersed in a fresh $\alpha$-MEM cell culture medium $\left(0.1 \mathrm{~g} \mathrm{~mL}^{-1}\right)$ at $37{ }^{\circ} \mathrm{C}$ for $72 \mathrm{~h}$. Briefly, the MC3T3-E1 cells were seeded in $35 \mathrm{~mm}$ confocal dishes with the scaffolds leached media at a density of $2 \times 10^{4}$ cells per well in a $\mathrm{CO}_{2}$ incubator at $37{ }^{\circ} \mathrm{C}$. After $24 \mathrm{~h}$ incubation, the media were removed. $1 \mathrm{~mL}$ of fresh medium was added to the control group and $1 \mathrm{~mL}$ of material extract was added to the test group. After the medium change, the cell morphology was investigated at 1 and 5 day(s) time points using Alexa Fluor ${ }^{\mathrm{TM}} 488$ phalloidin4',6-diamidino-2-phenylindole staining (FRTC Invitrogen, DAPI Sigma). Cell cultured dishes were rinsed with PBS twice. Then, specimens were fixed with $4 \%$ paraformaldehyde for $40 \mathrm{~min}$. After washing with PBS three times, the samples were permeabilized with PBS containing $0.2 \%$ Triton X-100 (Sigma) for $30 \mathrm{~min}$. After washing in PBS thrice, cells were incubated with FRTC for $30 \mathrm{~min}$. After washing again, the cells were incubated with DAPI for $10 \mathrm{~min}$. Fluorescence images were captured using a fluorescent inverted microscope (Nikon IS10, Melville, Japan).

\subsection{Cell viability test}

The cell viability on the scaffold was studied by fluorescein diacetate (FDA)/propidium iodide (PI) staining. Cell-seeded scaffolds were rinsed with PBS twice and then incubated with $10 \mu \mathrm{g} \mathrm{mL}^{-1}$ FDA and $20 \mu \mathrm{g} \mathrm{mL}^{-1}$ PI fresh culture medium at $37^{\circ} \mathrm{C}$ for $5 \mathrm{~min}$. The samples were washed twice using a PBS solution and then observed under the fluorescent inverted microscope. The viable-cell cytoplasm was stained green, while cell nuclei were stained red. Cells were also cultured with scaffold leached media to detect cell viability by FDA-PI staining. Cell viability was investigated at 1 and 5 day(s) time points.

\subsection{Proliferation testing-CCK-8 assay}

The proliferation of MC3T3-E1 cells on scaffolds was evaluated by using the Cell Counting Kit-8 (CCK-8) at different time points 

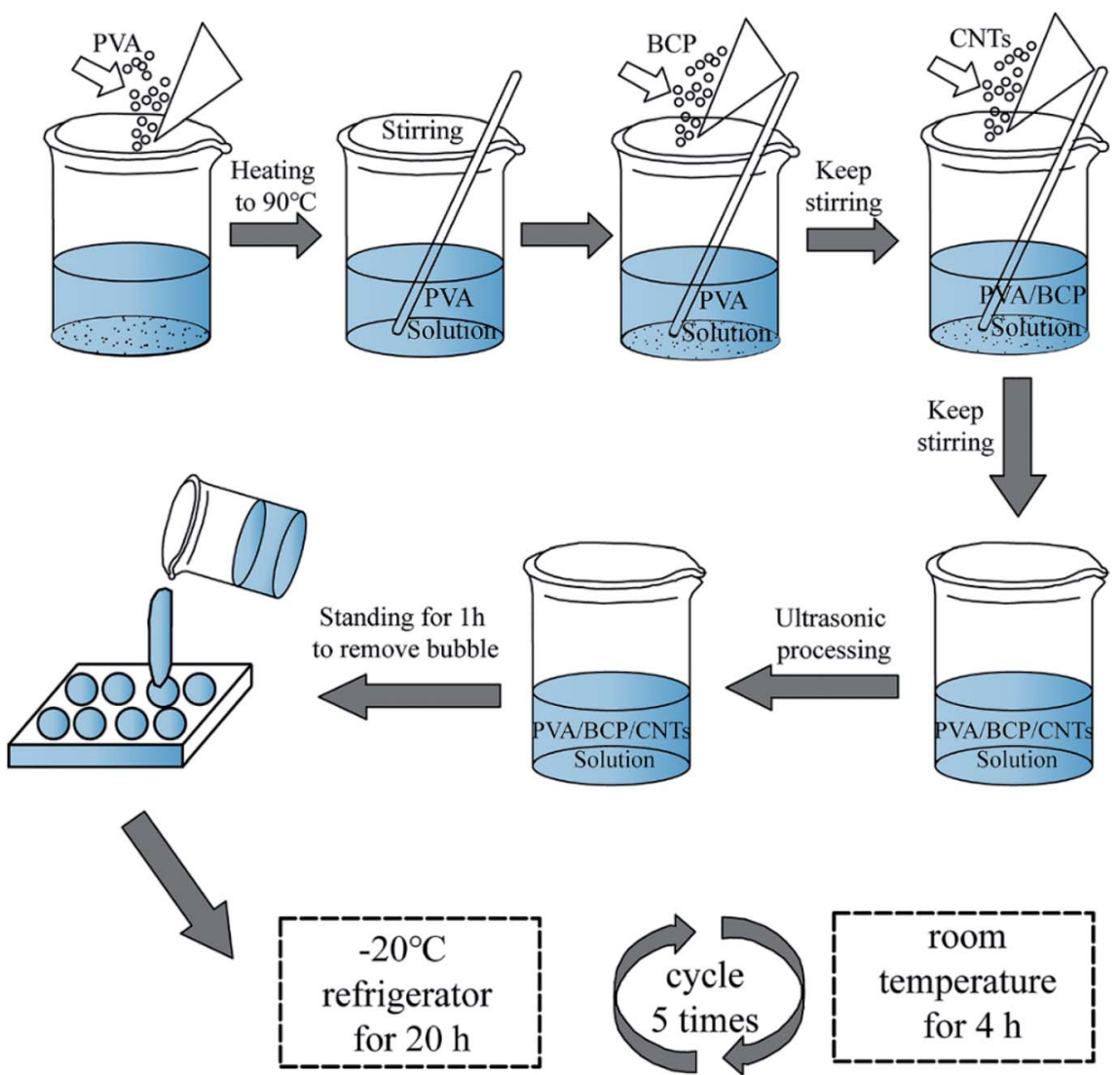

Fig. 1 Schematic illustration of the synthesis of hydrogels.

of 1, 3, 5 and 7 day(s) after seeding $(n=5) .2 \times 10^{4}$ cells per well were seeded on each different scaffolds and cultured in regular $\alpha$-MEM containing $10 \%$ fetal bovine serum and $1 \%$ antibiotic/ antimycotic in 24-well plates. At each time point, the culture medium was removed and refreshed with the $\alpha$-MEM medium with $10 \%$ CCK- 8 solution and cultured for another $4 \mathrm{~h}$. An
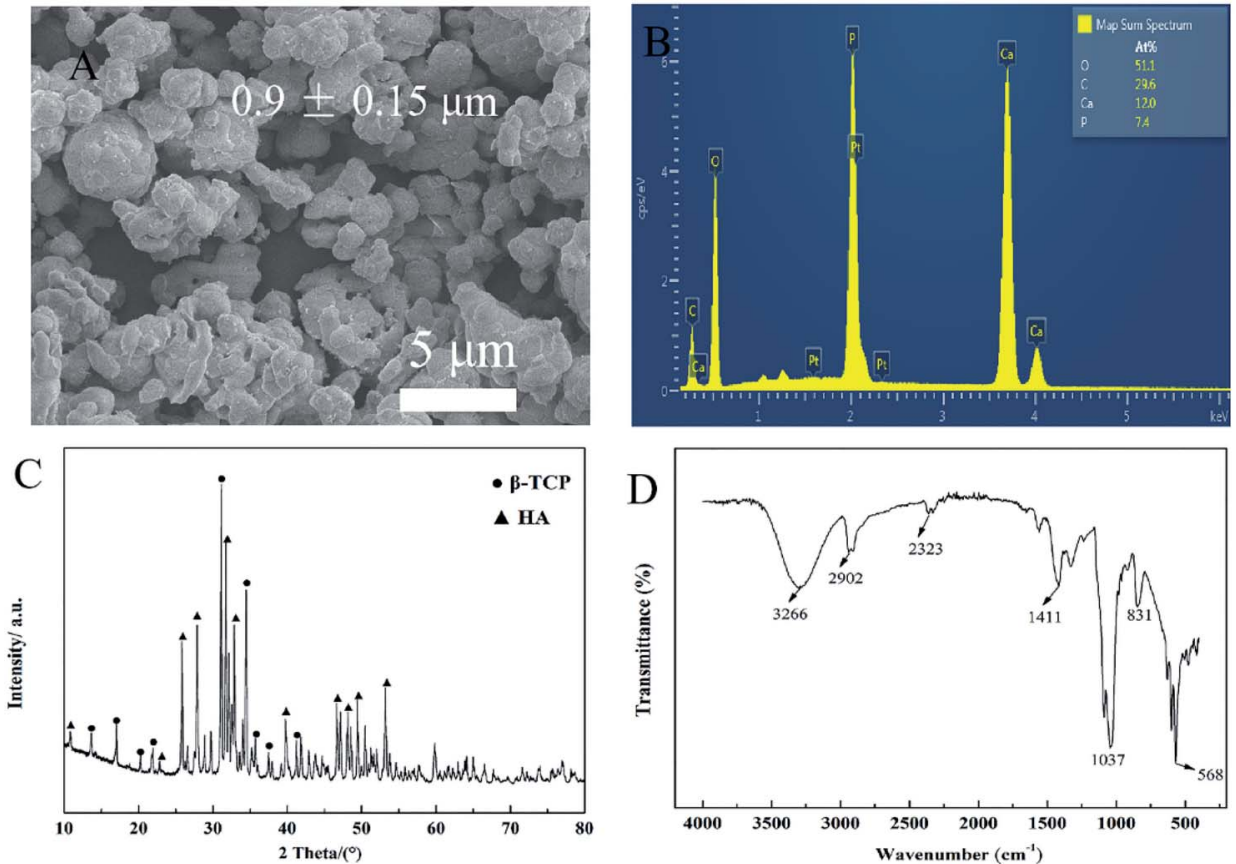

Fig. 2 Physical characterization of BCP powders. (A) SEM micrograph of BCP powders. (B) EDS analysis of BCP powders. (C) XRD pattern of BCP powders. (D) FTIR spectrum of BCP powders. 
aliquot from each well was removed to a new 96-well plate. The light absorbance was calculated at $450 \mathrm{~nm}$ with a microplate reader (Biorad iMark, US).
MC3T3-E1 cells were cultured with scaffold leached media to detect its proliferation by CCK-8 test. Briefly, cells were seeded on 96-well culture plate at a density of $1 \times 10^{4}$ cells per well in
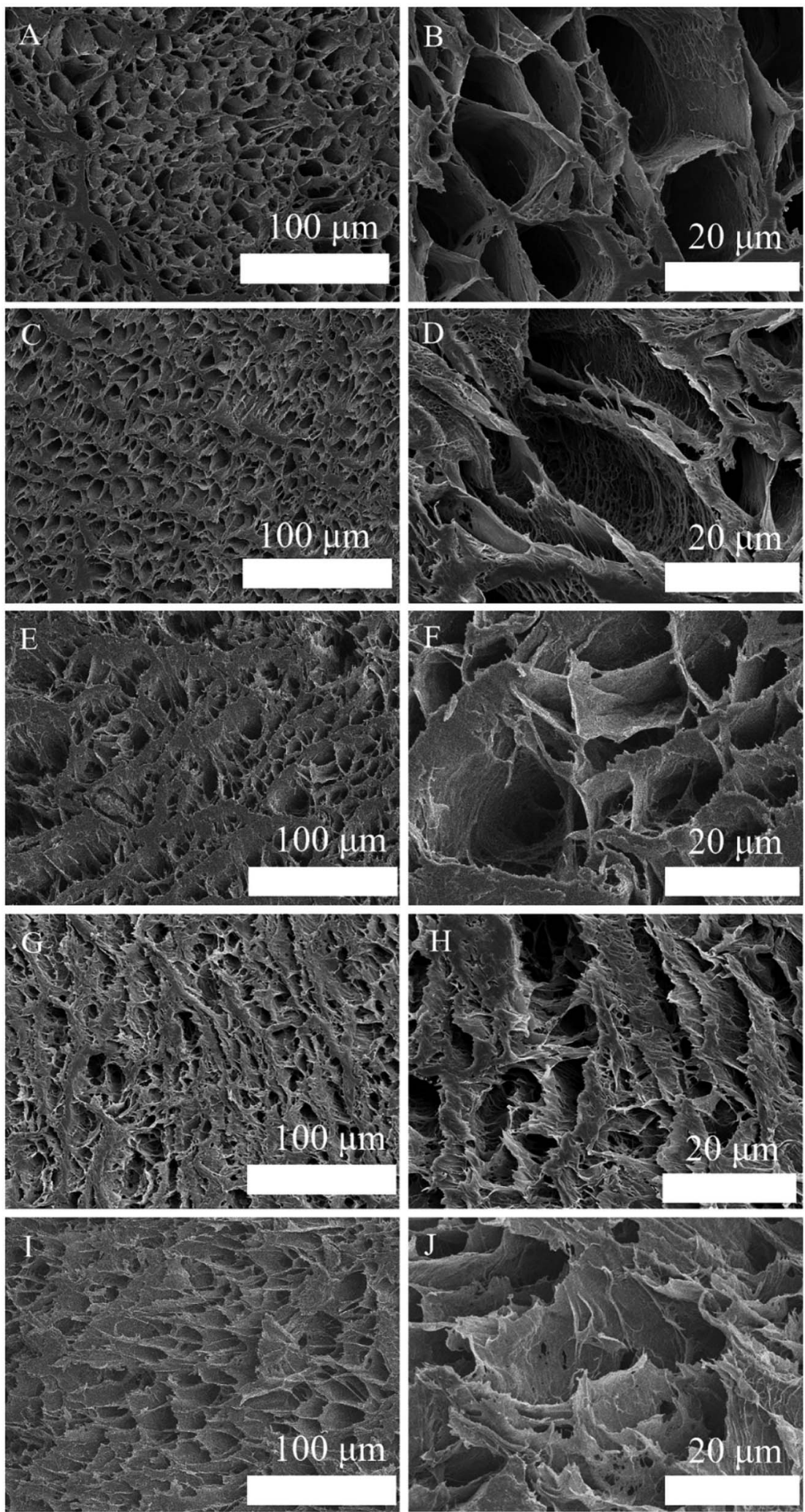

Fig. 3 SEM images of the morphologies and microstructures of the prepared porous scaffolds at different magnifications: (A and B) PVA scaffold, (C and D) PVA/BCP scaffold, (E and F) PVA/BCP/0.05\% CNT scaffold, (G and H) PVA/BCP/0.25\% CNTs and (I and J) PVA/BCP/0.5\% CNTs. 
a $\mathrm{CO}_{2}$ incubator at $37{ }^{\circ} \mathrm{C}$. Each group was made of 5 wells in parallel. After $24 \mathrm{~h}$ incubation, the media were removed. $100 \mu \mathrm{L}$ of fresh medium was added to the control group and $100 \mu \mathrm{L}$ of material extracts was added to the test group. At each time point, the culture medium was removed and refreshed with the $\alpha$-MEM medium with $10 \%$ CCK- 8 solution and then cultured for another $4 \mathrm{~h}$. The light absorbance was calculated at $450 \mathrm{~nm}$ with a microplate reader.

\subsection{Alkaline phosphatase (ALP) activity}

The ALP activity of cells $(n=5)$ was determined using an ALP assay kit (Beyotime, China). The medium was replaced with an osteoinductive medium at $72 \mathrm{~h}$ after seeding. The cells were lysed and collected after 7 and 14 days culture in osteoinductive media. Cells cultured on a dish with the osteoinductive medium were prepared as a control. Then, the lysates were reacted with $p$-nitro-phenyl phosphate ( $p$-NPP), and the absorbance of $p$ nitrophenol was determined at $405 \mathrm{~nm}$ using a microplate reader.

\subsection{Statistical analysis}

All quantitative data were analyzed by using SPSS 13.0. The results are presented as mean $\pm \mathrm{SE}$ values for each group. Statistical comparisons were carried out by using the Student's $t$-test or one-way ANOVA. Significance was defined as $P<0.05$.

\section{Results and discussion}

\subsection{Characterization of BCP powders}

In order to explain the properties of BCP powders, SEM, XRD, FTIR spectroscopy and EDS were employed. As shown in Fig. 2A, the SEM micrograph of BCP powders exhibited micro-nano particles with an almost uniform particle size. It shows that the BCP particles are almost round micro-nano particles, and the average diameter of particles is about $0.9 \pm 0.15 \mu \mathrm{m}$, which was calculated from SEM pictures by Image J program $(n=250)$. Furthermore, some micron scale agglomerates are observed.

The main elemental content of the BCP powders was examined by using EDS, which is presented in Fig. 2B. Calcium (Ca) and phosphorus $(\mathrm{P})$ were mapped to reflect the elemental ratio of $\mathrm{BCP}$, and the ratio of $\mathrm{Ca} / \mathrm{P}$ is almost 1.6.

Fig. 2C shows the XRD pattern of BCP powders after treating at $1150{ }^{\circ} \mathrm{C}$. Through the quantitative analysis of the XRD patterns, it confirms that BCP powders contain $40 \% \mathrm{HA}$ and $60 \% \beta$-TCP approximately. The HA and $\beta$-TCP peaks appeared in prepared BCP samples, the peaks at $2 \theta=10.8^{\circ}\left(\begin{array}{lll}1 & 0 & 0\end{array}\right), 25.8^{\circ}$ (l $\left.\begin{array}{lll}0 & 0 & 2\end{array}\right), 27.9^{\circ}\left(\begin{array}{lll}1 & 0 & 2\end{array}\right), 31.8^{\circ}\left(\begin{array}{lll}2 & 1 & 1\end{array}\right), 32.9^{\circ}\left(\begin{array}{lll}1 & 1 & 2\end{array}\right)$ and $39.8^{\circ}\left(\begin{array}{lll}3 & 1 & 0\end{array}\right)$ agree well with the diffraction peaks of HA crystals (JCPDS No. 9-0432). The peaks of $\beta$-TCP appear at $2 \theta=13.6^{\circ}\left(\begin{array}{lll}1 & 0 & 4\end{array}\right), 17.04^{\circ}$ (1 110 ), $20.2^{\circ}\left(\begin{array}{lll}2 & 0 & 2\end{array}\right), 21.9^{\circ}\left(\begin{array}{lll}2 & 1 & 1\end{array}\right)$ and $31.2^{\circ}\left(\begin{array}{llll}0 & 2 & 1 & 0\end{array}\right)$ (JCPDS No. 9-0169). According to the XRD pattern, there are no other impurities in BCP micro-nano powders.

BCP powders were analyzed via FTIR spectroscopy. As shown in Fig. 2D, phosphate ions, $\mathrm{PO}_{4}{ }^{3-}$, are the principal molecular components of BCP, contributing to the IR absorbance in the $1200-550 \mathrm{~cm}^{-1}$ region. The characteristic peaks at 1033 and
$1088 \mathrm{~cm}^{-1}$ correspond to the stretching vibration of $\mathrm{PO}_{4}{ }^{3-}$ and that at $599 \mathrm{~cm}^{-1}$ corresponds to the deformation vibrations of $\mathrm{PO}_{4}{ }^{3-}{ }^{2}$

\subsection{Scaffold characteristics}

3.2.1 SEM imaging. In bone tissue engineering, interconnected porous scaffolds play a critical role. Fig. 3 shows the low and high magnification SEM images of PVA scaffolds, PVA/ BCP scaffolds, PVA/BCP/0.05\% CNTs scaffolds, PVA/BCP/0.25\% CNTs scaffolds and PVA/BCP/0.5\% CNTs scaffolds. The SEM images show that the fabricated scaffolds are three dimensional with almost interconnected porous structures. The average pore sizes of different scaffolds are shown in Fig. 4. The pore sizes of PVA and PVA/BCP scaffolds vary from $4 \mu \mathrm{m}$ to $40 \mu \mathrm{m}$ as measured by SEM. The average pore sizes of PVA and PVA/BCP scaffolds are about $14.1 \pm 0.23 \mu \mathrm{m}$ and $13.5 \pm 0.39 \mu \mathrm{m}$, respectively, which have no significant difference between different groups $(P<0.05)$. After the addition of CNTs, the pore diameter of the scaffolds changes. For PVA/BCP/0.05\% CNT and $\mathrm{PVA} / \mathrm{BCP} / 0.25 \% \mathrm{CNT}$ samples, the pore size varies from $3 \mu \mathrm{m}$ to $31 \mu \mathrm{m}$, and their average pore sizes are about $8.6 \pm 0.26 \mu \mathrm{m}$ and $7.7 \pm 0.21 \mu \mathrm{m}$, respectively. However, when the content of CNTs increased to $0.5 \%$, the pore size of the $\mathrm{PVA} / \mathrm{BCP} / 0.5 \% \mathrm{CNT}$ scaffold increased from $4.2 \mu \mathrm{m}$ to $34.7 \mu \mathrm{m}$, and the average pore size increased up to $13.7 \pm 0.59 \mu \mathrm{m}$.

The $\mathrm{Ca}$ and $\mathrm{P}$ elemental distribution on the scaffold surface were mapped and merged to show the dispersion degree of BCP powders (Fig. 5). It shows that the $\mathrm{Ca}$ and $\mathrm{P}$ elements are uniformly distributed in the scaffolds with and without CNT incorporation. The $\mathrm{Ca} / \mathrm{P}$ ratios of both scaffolds are about 1.6.

3.2.2 XRD. XRD tests were carried out to confirm the crystal form of the particles. The diffraction patterns of PVA, PVA/BCP and PVA/BCP/0.25\% CNT scaffolds are shown in Fig. 6A. The XRD test for HA was also performed for comparison. In the PVA scaffold, a strong diffraction peak was observed at $2 \theta \approx 20^{\circ}$.

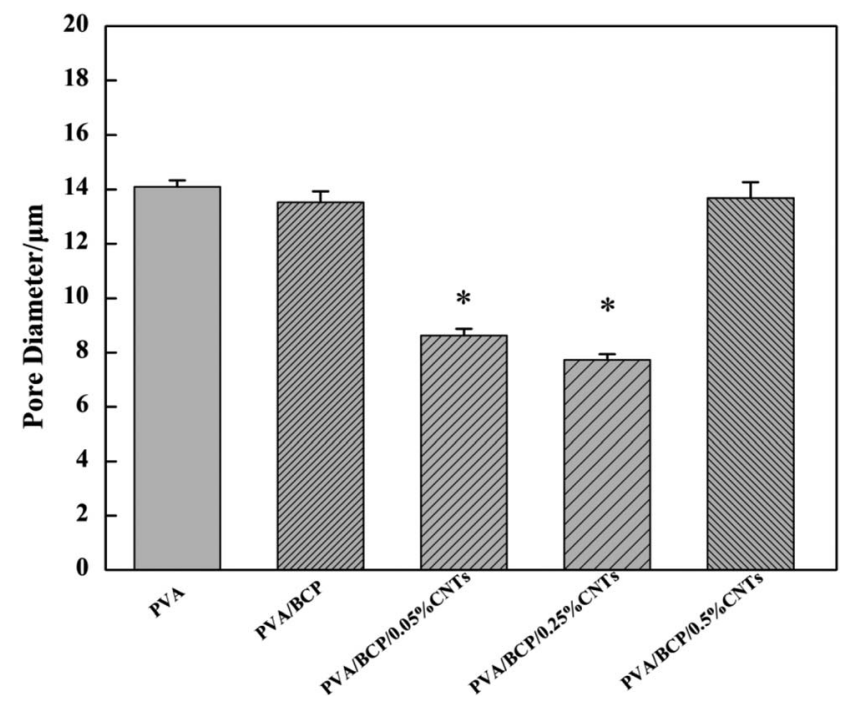

Fig. 4 The average pore size of scaffolds. Error bars represent the mean \pm standard error $(n \geq 250), * P<0.05$ compared to PVA group. 

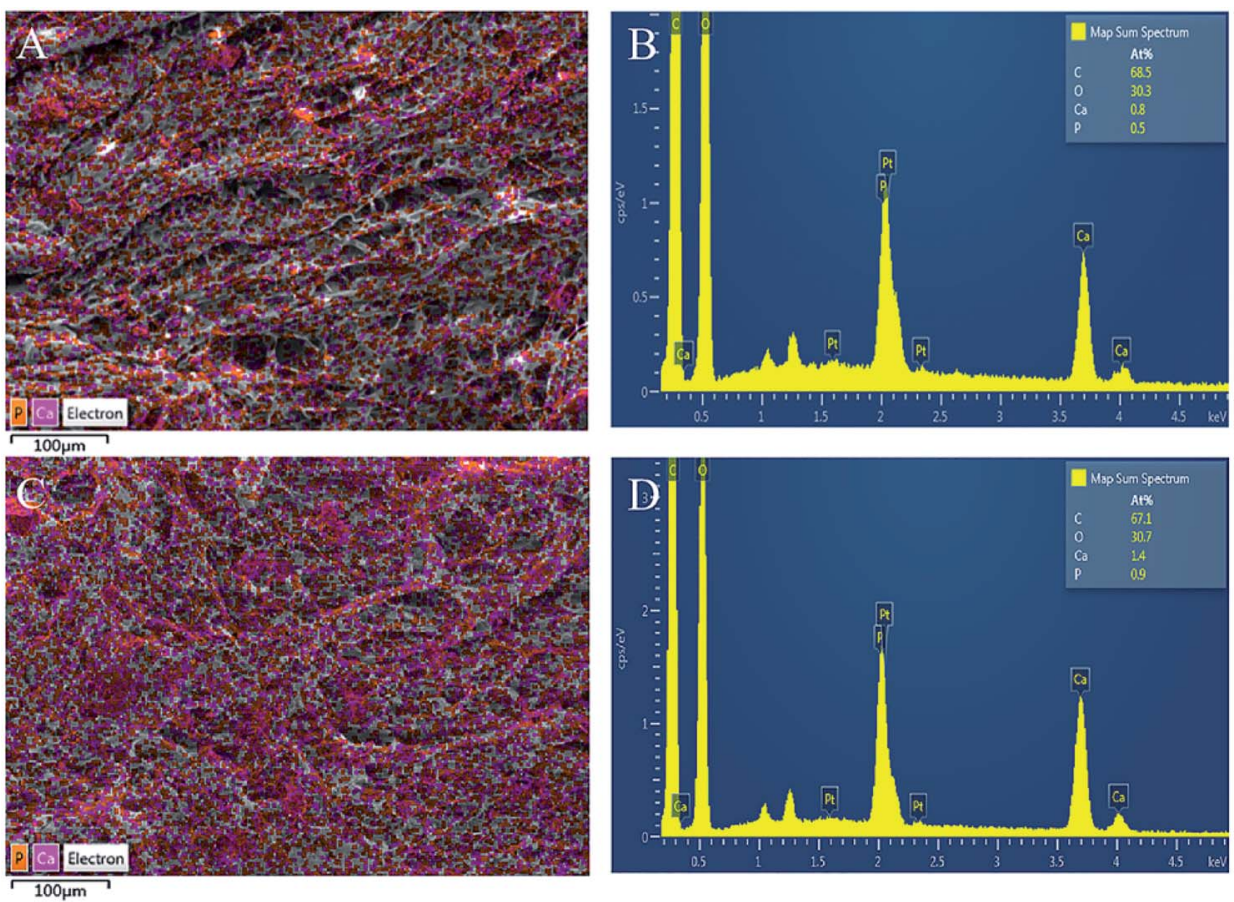

Fig. 5 EDS analysis of scaffolds. (A and B) EDS analysis of PVA/BCP scaffolds, (C and D) EDS analysis of PVA/BCP/0.25\% CNT scaffolds.

Meanwhile, the same peak was also observed in other group scaffolds, which corresponds to crystalline PVA. ${ }^{24}$ In other regions, the peaks belong to the BCP crystal, which has been analyzed in a previous section.

3.2.3 FTIR spectroscopy. FTIR spectroscopy was carried out to illustrate the molecular interactions among the components in the scaffolds to analyse some complex structural transformations that might have occurred due to the blending. Fig. 6B shows the FTIR spectra of PVA, PVA/BCP and PVA/BCP/ $0.25 \%$ CNT scaffolds. The FTIR spectrum of BCP was also obtained for comparison. The characteristic absorption bands of PVA appear at $3274 \mathrm{~cm}^{-1}$ (stretching of $\mathrm{OH}$ ), $2914 \mathrm{~cm}^{-1}$ (symmetric stretching of $\left.\mathrm{CH}_{2}\right), 1418 \mathrm{~cm}^{-1}(\mathrm{OH}, \mathrm{CH}$ bending, $\gamma\left(\mathrm{CH}_{2}\right), \delta(\mathrm{OH})$ ), $1087 \mathrm{~cm}^{-1}$ (stretching of $\mathrm{C}-\mathrm{C}$ and bending of $\mathrm{OH}$ (amorphous sequence of PVA)) and $831 \mathrm{~cm}^{-1}$ (rocking of $\left.\mathrm{CH}_{2}\right) .{ }^{6}$ After incorporating BCP micro-nano particles into PVA scaffolds, the main broad absorption band related to the $\mathrm{OH}$ stretching of PVA, which appeared at $3274 \mathrm{~cm}^{-1}$ wave number, shifted to a higher wave number region $\left(\mathrm{OH}=3284 \mathrm{~cm}^{-1}\right)$. This change proves that stronger hydrogen bonding may have been formed in the BCP/PVA scaffold compared to the pure PVA scaffold. It is owing to the increase in the number of $\mathrm{OH}$ groups after the addition of BCP micro-nano particles. The characteristic peaks at 1033 and $1088 \mathrm{~cm}^{-1}$ correspond to the stretching vibration of $\mathrm{PO}_{4}{ }^{3-} .{ }^{2}$ The peak of $\mathrm{PO}_{4}{ }^{3-}$ was overlapped with the stretching vibration peaks of $-\mathrm{C}-\mathrm{O}-$ in the crystalline region $\left(1142 \mathrm{~cm}^{-1}\right)$ and the amorphous region $\left(1089 \mathrm{~cm}^{-1}\right)$ of PVA. ${ }^{28}$

3.2.4 Porosity. Total porosities of the scaffolds were estimated by the liquid displacement method. Compared to PVA/ BCP hydrogels $(83.2 \pm 0.2 \%)$, the porosity of PVA hydrogels is higher $(87.7 \pm 0.6 \%)$. As the CNT concentration increases from $0.05 \%$ to $0.5 \%$ in $\mathrm{BCP} / \mathrm{PVA} / \mathrm{CNT}$ hydrogels, the porosity
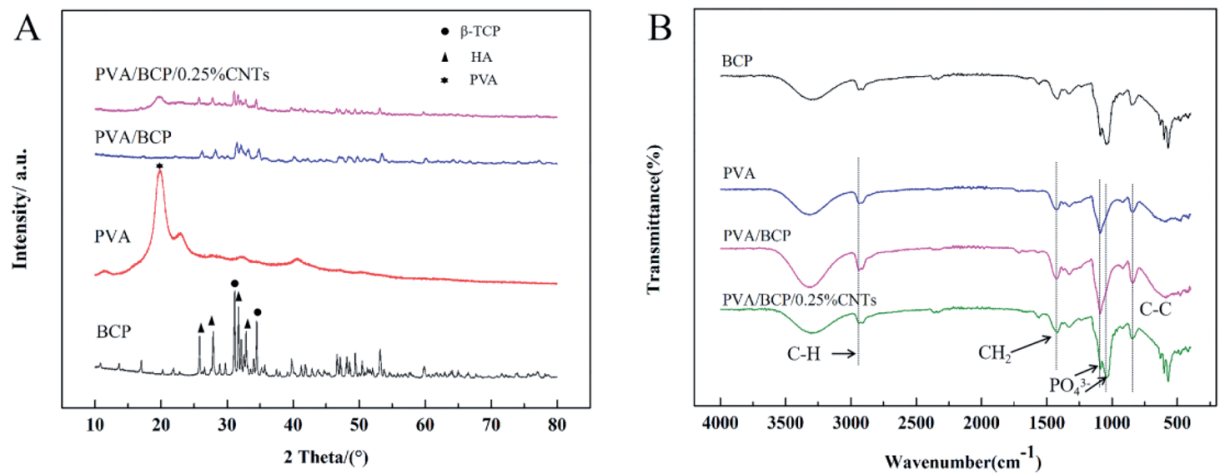

Fig. 6 XRD results and FTIR spectroscopy analyses of the samples. (A) XRD results, (B) FTIR spectroscopy analyses. 

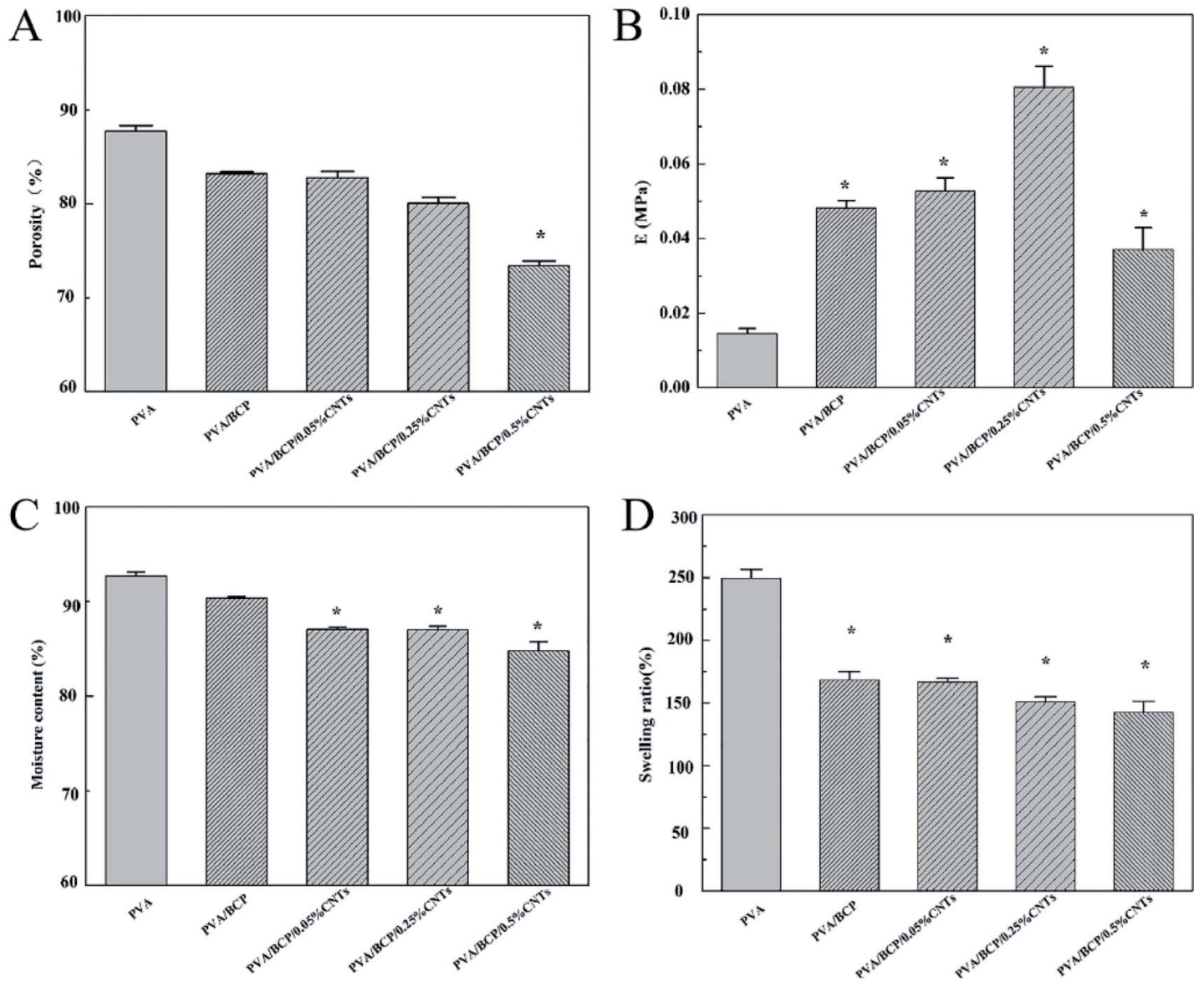

Fig. 7 The porosity, elasticity modulus, moisture content and swelling ratio analyses of samples. (A) Porosity results, (B) elasticity modulus, (C) moisture content and (D) swelling ratio. Error bars represent the mean \pm standard error. $* P<0.05$ compared to PVA group.

gradually decreases from $82.8 \pm 0.7 \%$ to $73.4 \pm 0.5 \%$ (Fig. $7 \mathrm{~A}$ ). The incorporation of CNTs into the hydrogels could reinforce the connections of the polymeric molecular chains. The bioactive groups, such as $-\mathrm{COOH}$ and $-\mathrm{OH}$, at the surface of $\mathrm{CNTs}$ could form hydrogen bonding with the -OH groups of PVA. It induces the final stable and tight structure. It may be the main reason for the reduced porosity of the hydrogels.

3.2.5 Mechanical properties. As one of the three core factors in tissue engineering, scaffolds play a fundamental role. An ideal scaffold should be a biomimetic ECM and meet the requirements of different tissues. ${ }^{25}$ Suitable mechanical properties of tissue engineering scaffolds are necessary for long-term structural and functional viability in vivo. Furthermore, mechanical properties of scaffolds have been shown to be a determining factor in directing cellular activity. ${ }^{26,27}$

The unconfined compressive strength of different hydrogels were investigated. According to Fig. $7 \mathrm{~B}$, the addition of $\mathrm{BCP}$ micro-nano particles into PVA results in a significant increase in the hydrogel's mechanical stiffness; a three-fold increase in the hydrogel stiffness is achieved from $15 \pm 1 \mathrm{kPa}$ to $48 \pm 2 \mathrm{kPa}$. There are some related research that have confirmed that BCP, HA and $\beta$-TCP could enhance the relevant mechanical properties of PVA. ${ }^{2,11,28}$ Nie et al. ${ }^{2}$ fabricated a well-developed porous $\mathrm{BCP} / \mathrm{PVA}$ scaffold. According to their study, the compressive strength of the scaffold was changed by the weight ratio of BCP/ PVA. According to the results, the stiffest group was the sample that contained $30 \%$ PVA. Further increase in the PVA

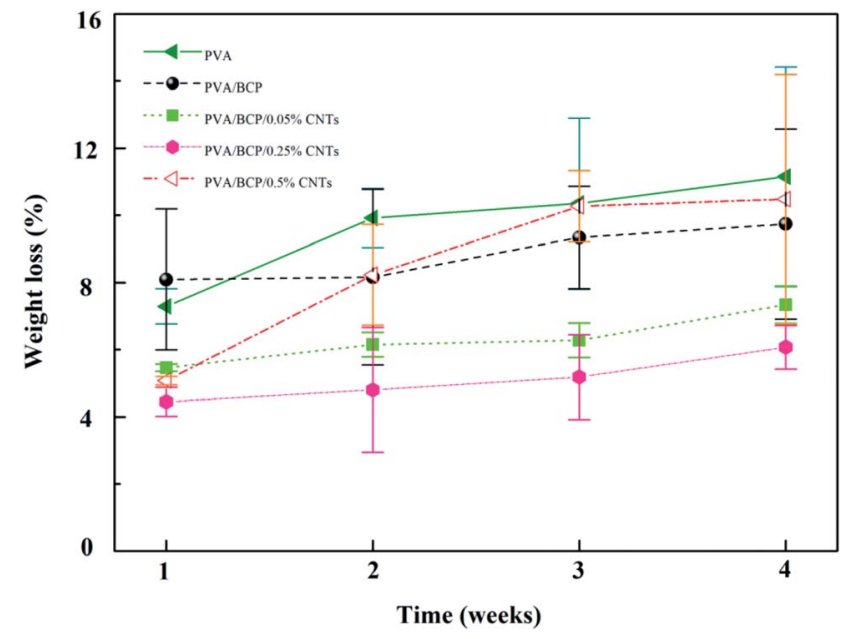

Fig. 8 The weight loss of the prepared scaffolds in the lysozyme solution after different soaking times. Error bars represent the mean \pm standard error, $n=5$. 

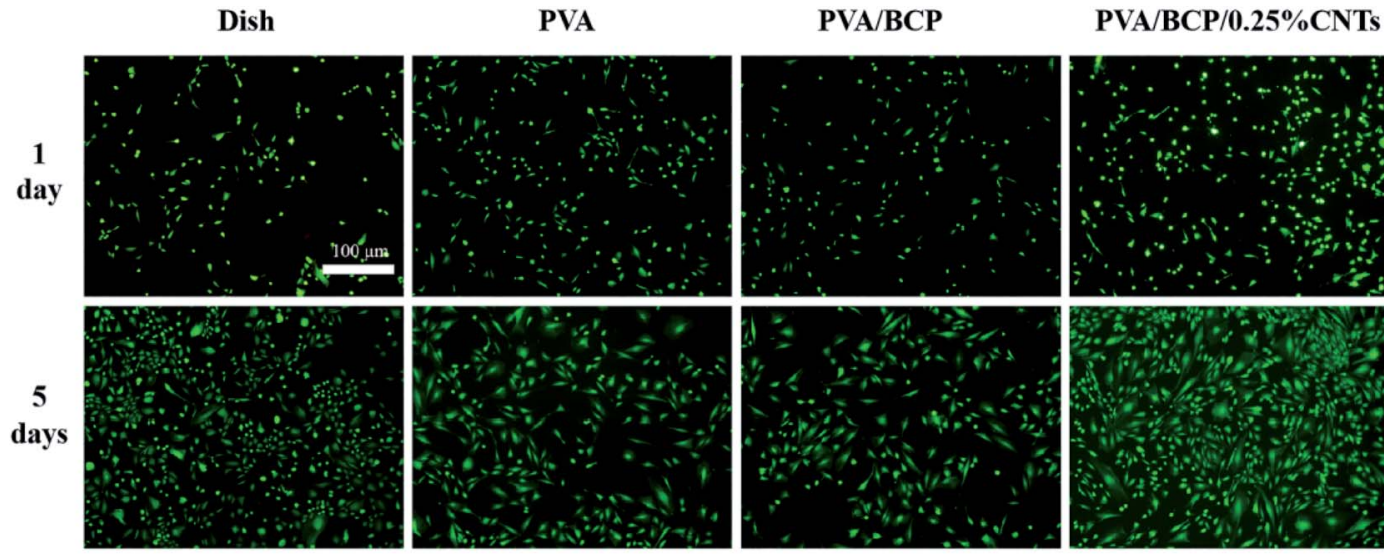

Fig. 9 The fluorescence images of FDA/PI stained cells cultured with scaffold extracts after culturing for 1 and 5 day(s). Scale bars: $100 \mu$ m.

concentration led to a decrease in the scaffold compressive strength. The scaffold compressive strength was reduced when the PVA concentration was up to $20 \%$, owing to the low concentration of the PVA component that led to the presence of the ceramic property in the scaffold. CNTs have attracted much attention because of its unique properties, such as conductivity, high surface-to-volume ratio, and chemical activity. ${ }^{18,29}$ As functional fillers, CNTs have been proposed to improve both mechanical and electrical properties for tissue engineering scaffolds. ${ }^{30} \mathrm{Xu}$ et $a l .{ }^{19}$ fabricated poly(lactic-co-glycolic acid)/ multi-wall carbon nanotube (PLGA/MWNT) composite electrospun fibrous scaffolds. Based on their results, the elastic modulus of electrospun fibers was increased by adding MWNTs at a concentration of $0.1 \%$. The increase in the content of MWNTs $(0.5 \%)$ will decrease the scaffold elastic modulus. Our result shows the same trends as shown in their results. With the increase in the CNT concentration from $0.05 \%$ to $0.25 \%$ in BCP/ $\mathrm{PVA} / \mathrm{CNT}$ hydrogels, the elasticity modulus gradually increased (from $53 \pm 4 \mathrm{kPa}$ to $81 \pm 6 \mathrm{kPa}$ ). However, further increase in the CNT content $(0.5 \%)$ led to a decrease in the elasticity modulus $(37 \pm 6 \mathrm{kPa})$. The result indicates that a right amount of CNTs could enhance the mechanical strength of BCP/PVA/CNT

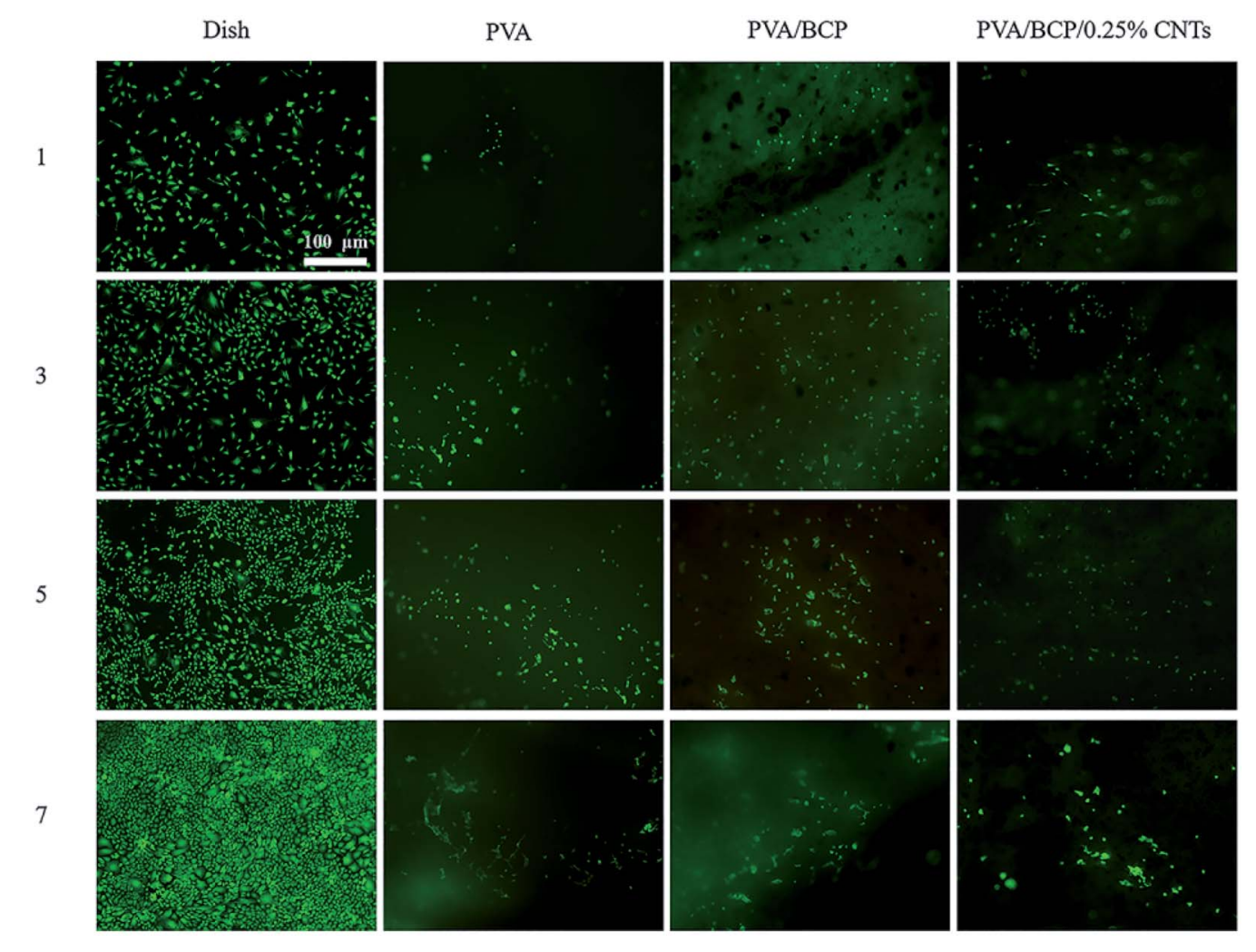

Fig. 10 Fluorescence images of FDA/PI staining of the scaffolds after cell culturing for 1, 3, 5 and 7 day(s). Scale bars: $100 \mu$ m. 

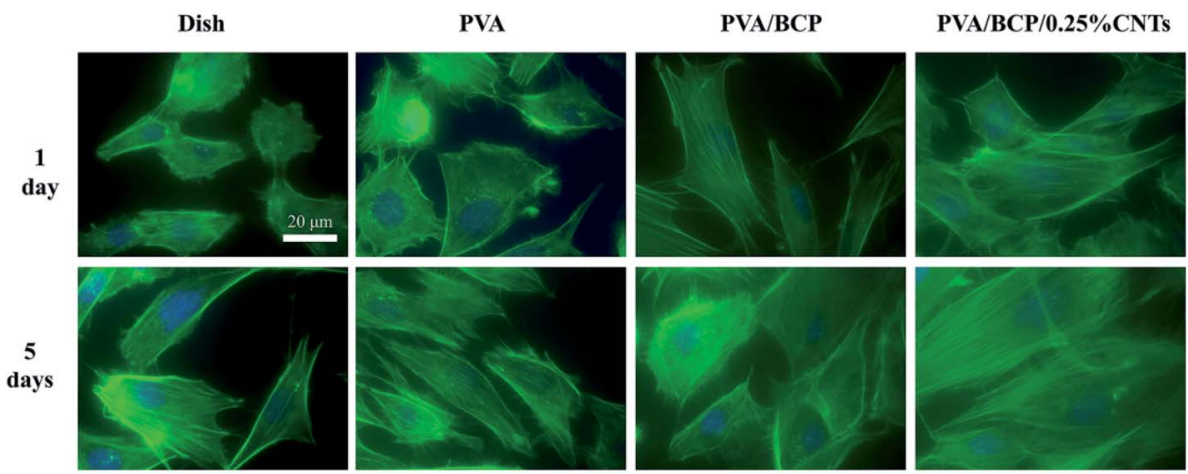

Fig. 11 The fluorescence images of FITC-DAPI stained cells cultured with scaffold extracts after culturing for 1 and 5 day(s). Scale bars: $20 \mu \mathrm{m}$.

scaffolds. Nevertheless, a large amount of CNTs may cause an uneven dispersion in the scaffold, which might damage the inner structure, leading to an adverse effect on the mechanical properties. $^{31}$ The pore size of scaffolds proves the point above. According to Fig. 3, lower CNT concentrations will decrease the pore diameter. However, when the CNT content is increased up to $0.5 \%$, the average pore size of the scaffold will increase.

3.2.6 Moisture content and swelling ratio. Swelling behavior is one of the key parameters that should be considered in a bone scaffold fabrication process because scaffolds should provide transportation for biological fluids. Most natural polymers swell readily in biological fluids. ${ }^{8}$ The moisture content and swelling ratio of scaffolds are shown in Fig. 7C and D. To be brief, with the incorporation of BCP micro-nano particles into PVA, the moisture content decreased from $93 \pm 0.5 \%$ to $90 \pm$ $0.2 \%$. But there was no significant difference between these two groups $(P>0.05)$. Meanwhile, the swelling ratio showed the same trend as above (from $250 \pm 7 \%$ to $168 \pm 7 \%$ ), but there were significant differences between these two groups $(P<0.05)$. As the CNT concentration increased from $0.05 \%$ to $0.5 \%$, both the swelling ratio and moisture content of scaffolds decreased gradually.

3.2.7 Degradation in lysozyme solution. Lysozyme is a common enzyme that exists in human body. Its levels in blood and serum are often raised when there is an inflammation or a microbial infection. To test the degradability of the scaffolds, the presence of this enzyme in PBS simulates the natural and inflammatory environment after a surgery. ${ }^{32}$ The degradation rate of each sample soaked in lysozyme solutions at different soaking times are presented in Fig. 8. It shows that the degradation rate of all samples increased with the soaking time. In summary, PVA/BCP scaffolds indicate a relatively lower degradation rate than PVA scaffolds. PVA scaffolds show a lower weight loss than PVA/BCP scaffolds at 1 week time point. The reason may be that some parts of the BCP powder that are not incorporated into the PVA matrix must have been dissolved in the lysozyme solution. With the increase in the CNT concentration from $0.05 \%$ to $0.25 \%$, the biodegradation ratio gradually decreased. Meanwhile, further increase in the CNT content to $0.5 \%$ led to a greater weight loss due to the change in the
A

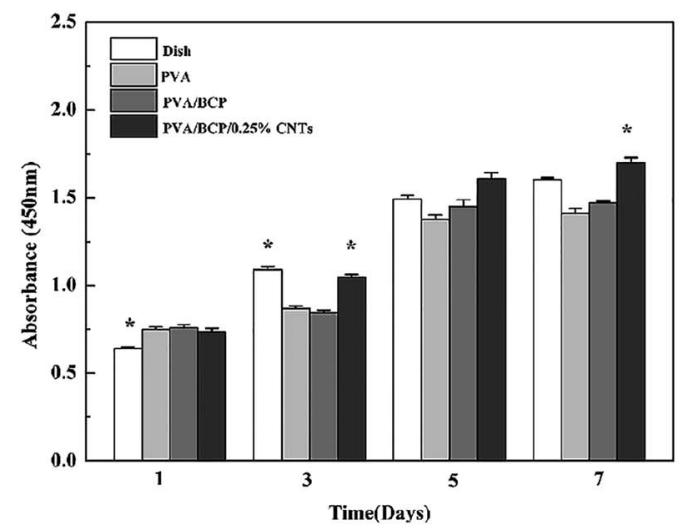

B

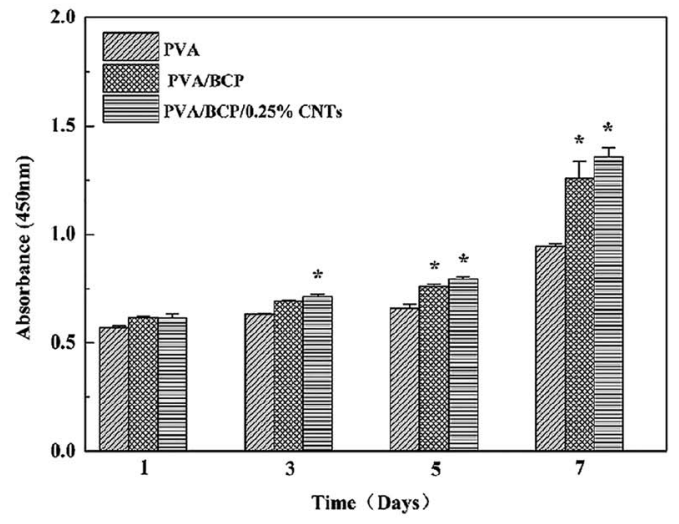

Fig. 12 CCK- 8 results. A. CCK- 8 results of cells cultured with scaffolds' extracts after culturing for $1,3,5$ and 7 day(s). Error bars represent the mean \pm standard error, ${ }^{*} P<0.05$ compared to PVA group at the same time point. B. CCK- 8 results after cells' culturing for $1,3,5$ and 7 day(s) on different sample surfaces. Error bars represent the mean \pm standard error, ${ }^{*} P<0.05$ compared to PVA group at the same time point. 


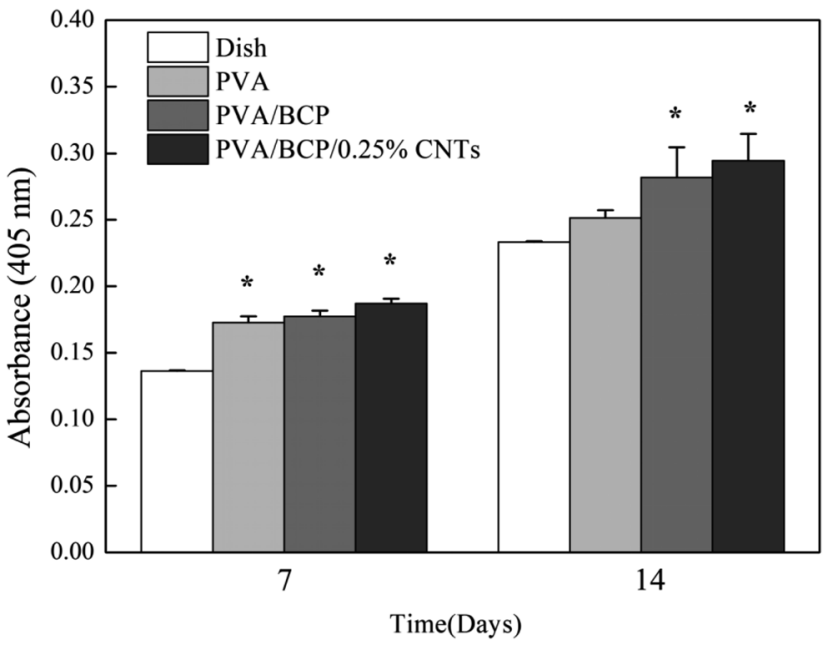

Fig. 13 ALP activity of cells on scaffolds after 7 and 14 days after seeding. Error bars represent the mean \pm standard error, $* P<0.05$ compared to dish group at the same time point.

scaffold inner structure and the increase in the average pore size.

\subsection{Cytocompatibility of scaffolds}

Based on the above experimental analysis results, we selected the group containing $0.25 \% \mathrm{wt} \%$ CNTs as the experimental group to conduct relevant cell experiments in vitro. Scaffolds fabricated for bone tissue engineering need good biocompatibility, which ensures a suitable environment for cell adhesion and proliferation. Viability of MC3T3-E1 cells cultured with scaffold extraction and on different scaffolds was analyzed using FDA/PI staining. According to Fig. 9 and 10, the cell viability of $\mathrm{PVA} / \mathrm{BCP}$ and $\mathrm{PVA} / \mathrm{BCP} / 0.25 \%$ CNT scaffolds is higher than that of pure PVA scaffolds. This might be due to the addition of BCP crystals in the scaffold.

Fig. 11 shows the cytoskeleton changes in the cells that were cultured with the extraction media of the scaffolds and the comparison with the control medium. At day 5, cells presented a more favorable spreading morphology than the first day. According to the fluorescence images of FITC-DAPI staining, cells cultured with PVA/BCP/0.25\% CNT scaffold extracts have a better spread and show more clearer stress fibers than the others.

The cell proliferation of different scaffolds was investigated through the CCK-8 assay. Cell proliferation with both scaffold extraction and on scaffolds was investigated. The results show that the CCK-8 absorption of cells either with scaffold extractions or on each scaffold increases with culture time, which indicates cell proliferation on all scaffolds (Fig. 12). Especially, MC3T3-E1 cells show a higher proliferation rate on the PVA/ $\mathrm{BCP} / 0.25 \%$ CNT scaffold than PVA and PVA/BCP groups. Cells cultured with $\mathrm{PVA} / \mathrm{BCP} / 0.25 \%$ CNT scaffold extracts have a higher proliferation rate that is even better than that of the dish groups at day 5 and day 7 .

ALP is an early-stage marker of osteogenic differentiation. ${ }^{15}$ Intracellular ALP activity was measured at 7 and 14 days after culture in osteoinductive media (Fig. 13). ALP expression was not significantly different between the four scaffold groups at day 7. However, both PVA/BCP/0.25\% CNT scaffolds and PVA/ BCP scaffolds had a higher absorbance than PVA at 14 days, which proves that the addition of BCP powder into scaffolds can promote the cell ALP activity. Meanwhile, ALP expression is significantly higher for the cells in all four scaffold groups than the cells in culture dishes.

To observe more detailed cell morphology, SEM was conducted to image the cell samples. As shown in Fig. 14, MC3T3-
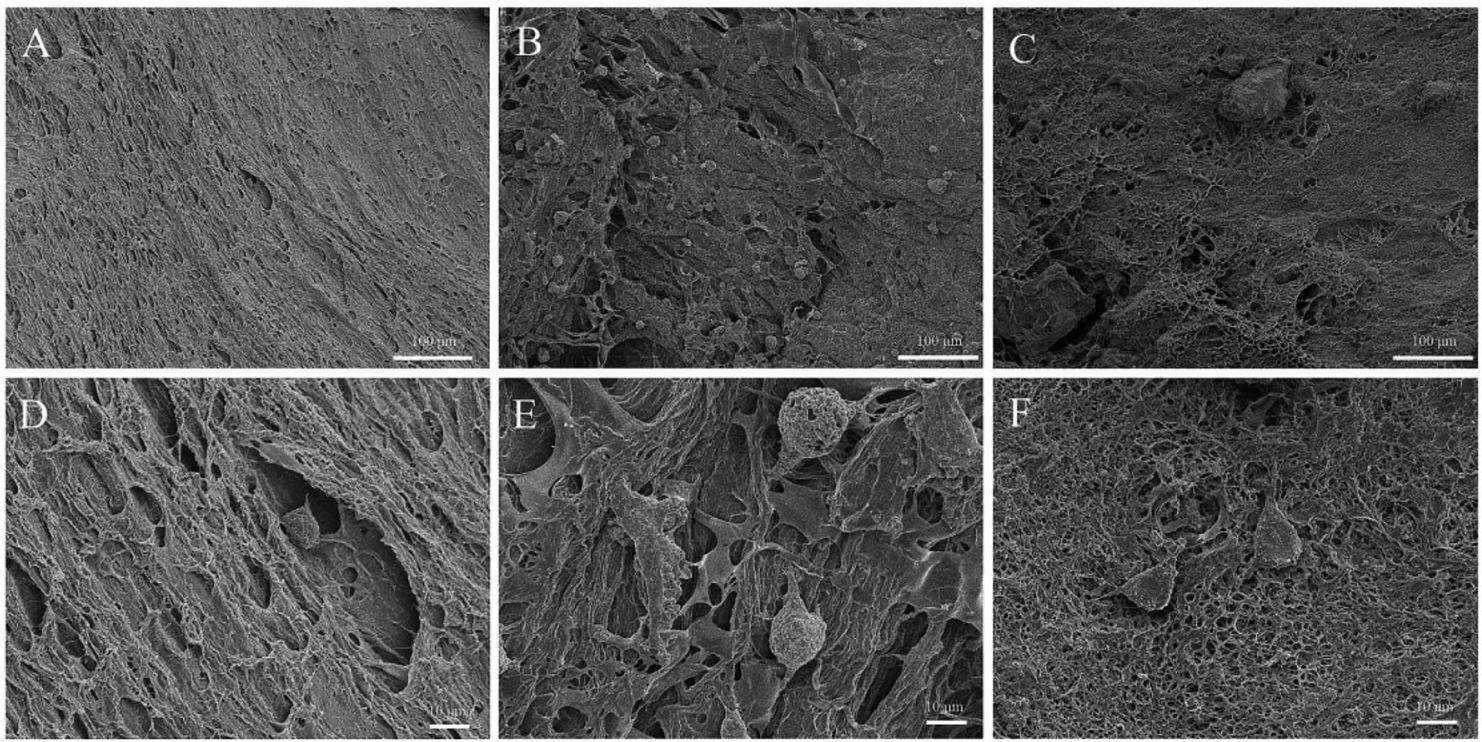

Fig. 14 MC3T3-E1 cells' morphologies observed by SEM after 1 day on scaffolds. (A and D) culturing on PVA scaffolds, (B and E) culturing on PVA/ BCP scaffolds, (C and F) culturing on PVA/BCP/0.25\% CNT scaffolds. 
A
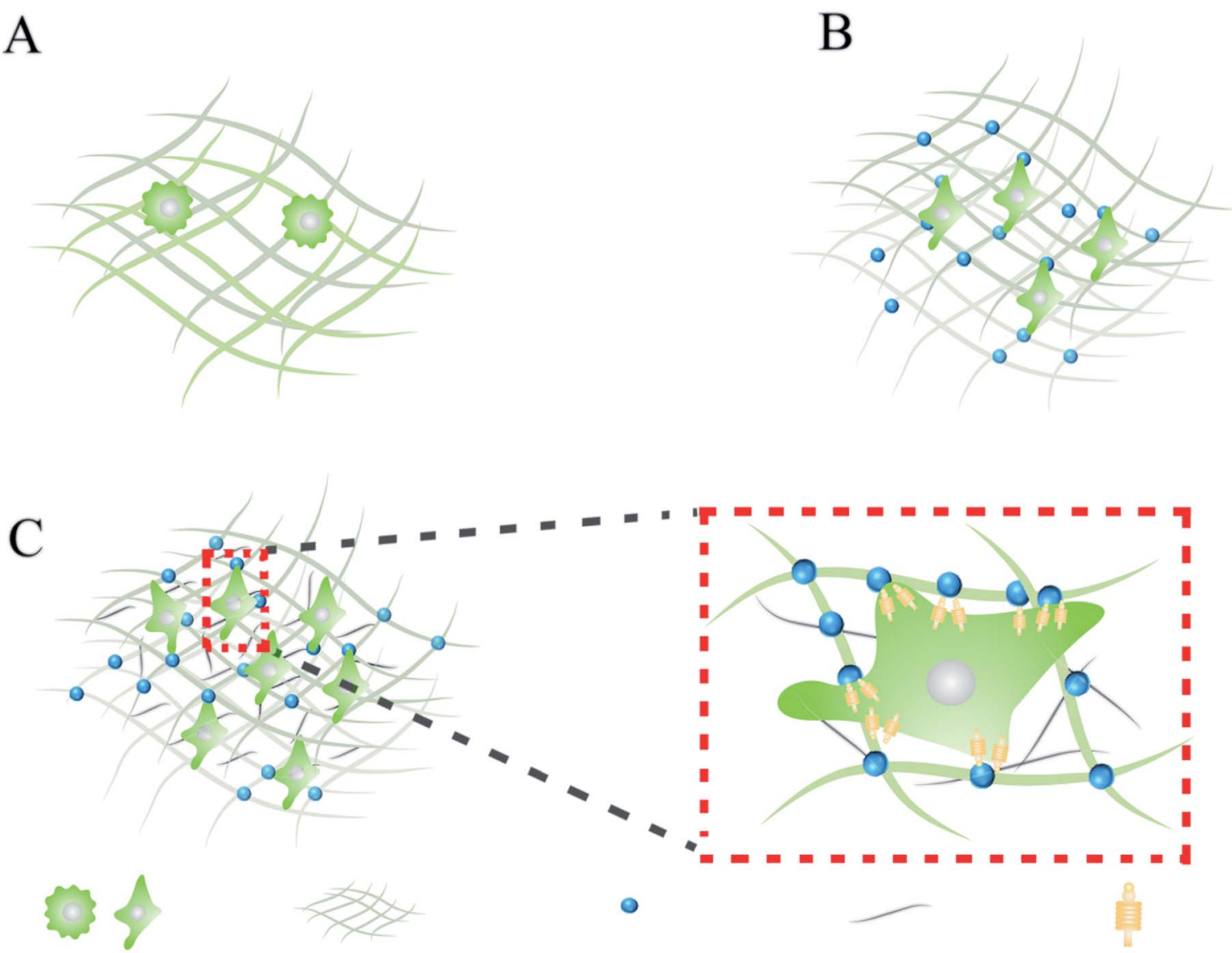

$\odot$

\section{MC3T3-E1 PVA scaffold BCP particles}

CNTs

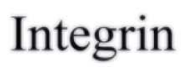

Fig. 15 Model of MC3T3-E1 cell culturing on different types of scaffolds.

E1 cells cultured on scaffolds exhibit a core-shell shape with an individually spread morphology. Much more cells are observed on PVA/BCP and PVA/BCP $/ 0.25 \%$ CNT scaffolds than pure PVA scaffolds. Furthermore, cells on PVA/BCP and PVA/BCP/0.25\% CNT scaffolds exhibit a more favorable spreading morphology.

Despite the fact that PVA exhibits a good biocompatibility, ${ }^{33,34}$ there are some research that show that PVA scaffold shows a low or no adhesion to cells as a hydrophilic material. $^{35-37}$ In order to improve the cell attachment properties of PVA hydrogels, HA and BCP are frequently used.,.$^{2,11,17}$ As in our present research, on a pure PVA scaffold, there is rarely few cells observed on the surface, proving that pure PVA has a poor nonadhesive property. However, on PVA/BCP scaffolds, due to the incorporation of BCP micro-nano particles, much more cells are detected to be attached to the surface, and some cells have even begun to spread and proliferate. It proves that cells prefer to get adhered onto the PVA/BCP scaffolds than pure PVA scaffolds. It can be seen that there is more cell adhesion and a better proliferation rate on PVA/BCP/CNT when the CNTs are added into the scaffolds. The reason may be the addition of BCP powder into the scaffolds, which contribute to more anchoring points that cells adhere to. Meanwhile, the right amount of CNT addition will increase the crosslinking degree of scaffolds, which would further increase the cell adhesion anchoring points (Fig. 15). According to the SEM figures, the cells are not confluent on both surfaces of $\mathrm{PVA} / \mathrm{BCP}$ and $\mathrm{PVA} / \mathrm{BCP} / \mathrm{CNT}$ scaffolds. The reason may be that although the addition of BCP powder and CNTs enhances the mechanical properties of scaffolds to a certain level, their elastic modulus is relatively low compared to natural cartilage..$^{37}$ The activity of cell adhesion is dependent not only on the substrate's rigidity but also on the relative rigidity between the cell and the substrate. Cells tend to grow on substrates that are as rigid as themselves. ${ }^{38}$

\section{Conclusion}

$\mathrm{PVA} / \mathrm{BCP} / \mathrm{CNT}$ hydrogels with high interconnectivity, a porous structure, a medium elastic modulus and good biocompatibility were fabricated in the present research. The elasticity modulus of pure PVA hydrogels is about $15 \pm 1 \mathrm{kPa}$. Blending BCP powder into PVA increased the elasticity modulus to $48 \pm 2 \mathrm{kPa}$. The introduction of CNTs $(0.05 \%$ and $0.25 \%)$ and $5 \%$ BCP particles increased the elasticity modulus of the PVA/BCP/CNT hydrogel from $53 \pm 4 \mathrm{kPa}$ to $81 \pm 6 \mathrm{kPa}$. With further increase in the CNT concentration to $0.5 \%$, the elastic modulus decreased to $37 \pm 6 \mathrm{kPa}$. In addition, the PVA/BCP $/ 0.25 \% \mathrm{CNT}$ 
hydrogels exhibited good cytocompatibility. CCK-8 results show a higher cell proliferation ratio on $\mathrm{PVA} / \mathrm{BCP} / 0.25 \%$ CNT hydrogels than the others. In conclusion, the fabricated PVA/ $\mathrm{BCP} / \mathrm{CNT}$ hydrogels could meet the basic requirements of bone tissue engineering and regeneration.

\section{Conflicts of interest}

There are no conflicts to declare.

\section{Acknowledgements}

This work has been supported by the Natural Science Foundation of China (Grant no. 11632013, 11572213, 11502158). The support of the International Cooperation Project Foundation of Shanxi Province (Grant no. 201803D421060) and the Natural Science Foundation for Young Scientist of Shanxi Province, China (201801D221439) is also acknowledged with gratitude.

\section{References}

1 L. Bai, Z. Du, J. Du, W. Yao, J. Zhang, Z. Weng, S. Liu, Y. Zhao, Y. Liu, X. Zhang, X. Huang, R. Hang, D. Huang, B. Tang and Y. Xiao, Biomaterials, 2018, 162, 154-169.

2 L. Nie, D. Chen, J. Suo, P. Zou, S. Feng, Q. Yang, S. Yang and S. Ye, Colloids Surf., B, 2012, 100, 169-176.

3 T. Kurien, R. Pearson and B. Scammell, Bone Joint. J., 2013, 95, 583-597.

4 W. Ji, X. Zhang and Y. Qiu, World J. Exp. Med., 2016, 6, 58-62. 5 D. Algul, A. Gokce, A. Onal, E. Servet, A. I. D. Ekici and F. Yener, J. Biomater. Sci., Polym. Ed., 2016, 27, 10.

6 A. Asran, S. Henning and G. Michler, Polymer, 2010, 51, 868876.

7 J. Li, S.-I. Roohani-Esfahani, K. Kim, D. Kaplan and H. Zreiqat, J. Tissue Eng. Regener. Med., 2017, 1, 1741-1753.

8 W. Yanen, W. Kai, L. Xinpei, W. Qinghua, C. Weihong, W. Shuzhi, Y. Che, T. Lu and B. Zhang, PLoS One, 2017, 12, e0174870.

9 A. Derya, H. Sipahi, A. Aydin, F. Kelleci, S. Ozdatli and F. Yener, Int. J. Biol. Macromol., 2015, 79, 363-369.

10 Z. Wei, C. Zhang, K. Duan, X. Li, S. Qu, J. Wang, Z. Zhu, P. Huang, T. Xia, G. Liao and J. Wen, J. Biomed. Mater. Res., Part A, 2014, 102, 2491-2501.

11 C. Su, Y. Su, Z. Li, M. Haq, Y. Zhou and D. Wang, Mater. Sci. Eng., C, 2017, 77, 76-83.

12 A. K. Guha, S. Singh, R. Kumaresan, S. Nayar and A. Sinha, Colloids Surf., B, 2009, 73, 146-151.

13 X. Li, S. Yan, J. Dai, Y. Lu, Y. Wang, M. Sun, J. Gong and Y. Yao, Colloids Surf., B, 2017, 162, 390-397.

14 J. M. Yang, J. H. Yang, S. C. Tsou, C. H. Ding and J. S. Wang, Mater. Sci. Eng., C, 2016, 66, 170-177.
15 N. S. Ibrahim, G. Krishnamurithy, R. B. R. Hanumantha, S. Puvaneswary, N. Wuey Min and T. Kamarul, Mater. Lett., 2013, 113, 25-29.

16 W. Li, J. Kang, Y. Yuan, F. Xiao, H. Yao, S. Liu, J. Lu, Y. Wang, Z. Wang and L. Ren, Compos. Sci. Technol., 2016, 128, 58-64.

17 H. Yao, J. Kang, W. Li, J. Liu, R. Xie, Y. Wang, S. Liu, D. Wang and L. Ren, Biomed. Mater., 2017, 13, 015012.

18 S. Iijima, Nature, 1991, 354, 56-58.

19 J. Xu, Y. Xie, H. Zhang, Z. Ye and W. Zhang, Colloids Surf., B, 2014, 123, 907-915.

20 D. Huang, Q. Lin, M. Yin, J. Du, Y. Wei, Y. Hu and W. Chen, J. Biomater. Sci., Polym. Ed., 2019, 30, 1744-1755.

21 D. Y. Kim, Y. H. Han, J. H. Lee, I. K. Kang, B. K. Jang and S. Kim, BioMed Res. Int., 2014, 768254.

22 Z. Lu, Y. Zhai, N. Wang, Y. Zhang, P. Xue, M. Guo, B. Tang, D. Huang, W. Wang, Z. Bai and S. Dou, Chem. Eng. J., 2020, 380, 122455.

23 Y. H. Meng, C. Y. Tang, C. P. Tsui and D. Z. Chen, J. Mater. Sci.: Mater. Med., 2008, 19, 75-81.

24 R. Ricciardi, F. Auriemma, C. De Rosa and L. Franoise, Macromolecules, 2004, 37, 1921-1927.

25 N. H. Dormer, C. J. Berkland and M. S. Detamore, Ann. Biomed. Eng., 2010, 38, 2121-2141.

26 A. J. Engler, L. Richert, J. Y. Wong, C. Picart and D. E. Discher, Surf. Sci., 2004, 570, 142-154.

27 A. J. Engler, S. Sen, H. L. Sweeney and D. E. Discher, Cell, 2006, 126, 677-689.

28 J. Zhu, L. Li and Q. Wang, J. Appl. Polym. Sci., 2017, 134, 16. 29 N. Saito, Y. Usui, K. Aoki, N. Narita, M. Shimizu, K. Hara, N. Ogiwara, K. Nakamura, N. Ishigaki, H. Kato, S. Tarutac and M. Endoc, Chem. Soc. Rev., 2009, 38, 1897-1903.

30 S. L. Edwards, J. A. Werkmeister and J. A. M. Ramshaw, Carbon nanotubes in scaffolds for tissue engineering, Expert Rev. Med. Devices, 2009, 6, 499-505.

31 K. P. Ryan, M. Cadek, V. Nicolosi, D. Blond, M. Ruether, G. Armstrong, H. Swan, A. Fonseca, J. Nagy, W. Maser, W. Blau and J. Coleman, Compos. Sci. Technol., 2007, 67, 1640-1649.

32 H. Y. Lin, W. C. Tsai and S. H. Chang, J. Biomater. Sci., Polym. Ed., 2017, 28(7), 664-678.

33 M. Kobayashi, Y. S. Chang and M. Oka, Biomaterials, 2005, 26, 3243-3248.

34 W. Wan, A. D. Bannerman, L. Yang and H. Mak, Adv. Polym. Sci., 2014, 263, 283-321.

35 S. Bhowmick and V. Koul, Mater. Sci. Eng., C, 2016, 59, 109119.

36 Y. Liu, N. E. Vrana, P. A. Cahill and G. B. Mcguinness, J. Biomed. Mater. Res., Part B, 2009, 90, 492-502.

37 C. R. Nuttelman, D. J. Mortisen, S. M. Henry and K. S. Anseth, J. Biomed. Mater. Res., 2001, 57, 217-223.

38 Y. Ni and M. Y. M. Chiang, Soft Matter, 2007, 3(10), 1285. 